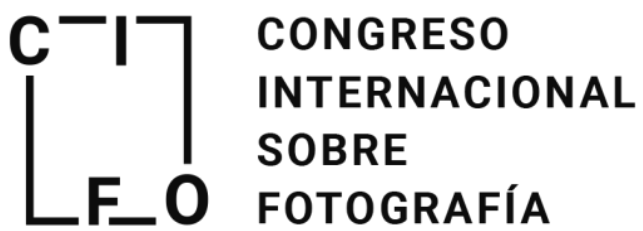

Congreso Internacional sobre Fotografía

UPV, 5 y 6 octubre 2017

Doi:http://dx.doi.org/10.4995/CIFo17.2017.7128

ISBN: 978-84-9048-604-7

\section{Fundamentos de Fotografia y Arquitectura}

Javier Boned Purkiss, Javier López Rivera, Ferran Ventura Blanch, Jorge Yeregui Tejedor.

(Universidad de Malaga, fjboned@uma.es), (Universidad de Sevilla, lrivera@us.es), (Universidad de Malaga, ferranventura@uma.es),(Universidad de Malaga,n3.jorge@gmail.com).

\begin{abstract}
In the academic context of the Andalusian universities, the course named Fundamentals of Photography and Architecture introduces as a first novelty the coordination between the schools of architecture of Seville and Malaga, as well as between the Universities of both cities. It is a pioneering project never proposed in the Andalusian framework, composed of a scientific committee, a cadre of professors and a teaching program unique for both sites. Not without effort, are the teachers who moves between both sites to establish, through teaching, a connection and achieve interprovincial coordination between two educational centers with shared concerns. Finally, it's the joint interest in the relationship between photography and architecture, which has motivated the development for the first time in Andalusia of an educational program of an autonomous nature that advocates directly for interuniversity collaboration and for the development of a coordinated research and training, based on the knowledge.
\end{abstract}

Keywords: photography, architecture, ideas, narration, discard.

\section{Resumen}

En el marco académico de las universidades andaluzas, el curso Fundamentos de Fotografía y Arquitectura introduce como primera novedad la coordinación entre las escuelas de arquitectura de Sevilla y Málaga, así como entre las Universidades de ambas ciudades. Se trata de un proyecto pionero nunca propuesto en el marco andaluz, compuesto por un comité cientifico, un cuadro de profesores y un programa docente únicos para ambas sedes. No sin esfuerzo, es el profesorado el que se desplaza entre ambos emplazamientos para, a través de la docencia, establecer una conexión y conseguir una coordinación interprovincial entre dos centros educativos con inquietudes compartidas. Finalmente, es el interés conjunto por la relación entre fotografia y arquitectura, el que ha motivado el desarrollo por primera vez en Andalucía de un programa educativo de carácter autonómico que aboga directamente por la colaboración interuniversitaria y por el desarrollo de una investigación y una formación coordinadas y basadas en el conocimiento.

Palabras clave: fotografia, arquitectura, ideas, narración, descarte 


\section{Introducción}

El pasado curso escolar 2015-16, dos grupos de trabajo integrados por miembros pertenecientes a la Universidad de Sevilla y a la Universidad de Málaga, prepararon y desarrollaron en sus respectivas sedes sendos cursos cortos de Extensión Universitaria $-3,5$ créditos- con temática similar, con un carácter teórico-práctico y enfocados a la vinculación entre fotografía y arquitectura (denominados respectivamente, Visiones arquitectónicas de la Fotografía-Sevilla y Fundamentos de Arquitectura y Fotografia-Málaga). Animados por la buena acogida y los resultados obtenidos, nació un intento por aunar esfuerzos y crear un programa y equipo común de trabajo de carácter territorial, que pudiera ser impartido en ambas sedes.

Y así, en este curso 2016-17 recien terminado, se ha desarrollado -con satisfactorios resultados- un Curso de Formación Contínua de 7 créditos, denominado Fundamentos de Fotografía y Arquitectura, y cuyo desarrollo y resultados suponen el objeto esencial de esta comunicación, que pasaremos a desarrollar en los apartados siguientes. Pero la historia no acaba aquí, pues para el curso que nos ocupa 2017-18, y animados por los resultados obtenidos, está previsto ofertar en ambas sedes un Curso de Experto en Fotografía y Arquitectura, de 15 créditos, como un paso intermedio más en el camino hacia el objetivo final, que no puede ser otro que la creación de un Máster Propio en Fotografía y Arquitectura (60 créditos), de marcado carácter y ámbito andaluz, pero con destacada presencia internacional.

El curso Fundamentos de Fotografia y Arquitectura, en el que se centrará esta comunicación, tuvo carácter presencial y contenido teórico-práctico, primando este segundo carácter frente al primero. Se desarrolló a lo largo del segundo cuatrimestre, en 16 sesiones de tarde -una por semana-, de 4/5 horas de duración cada una, hasta alcanzar las 70 horas presenciales. La estructura docente se desarrolla en base a 4 módulos, de los cuales dos son teóricos (29\%); y los otros dos de carácter práctico (71\%). Los módulos compartieron su presencia generalmente dos por sesión- a lo largo del curso, alternándose de forma cronológica los contenidos teóricos con los prácticos y los técnicos, evitando con ello la monotonía y la concentración de temáticas o actividades.

La estructura organizativa, el comité científico y el cuadro de profesores fue único, si bien el curso se impartió de forma independiente en las sedes de las ETS Arquitectura de Sevilla y Málaga, en días consecutivos (miércoles y jueves respectivamente, en horario de tarde). De este modo, fueron los profesores -y no los alumnos- los que se desplazaron, pudiendo admitir el cupo máximo de alumnos ofertado en cada una de las sedes, aunque finalmente sólo se alcanzaron 10 y 9 alumnos respectivamente.

La estructura docente se desarrolló a lo largo de 4 módulos, de los cuales dos fueron teóricos (29\% horas lectivas); y otros dos fueron de carácter práctico (71\%). Los módulos fueron compartiendo su presencia generalmente dos por sesión- a lo largo del curso, alternándose de forma cronológica los contenidos teóricos con los prácticos y los técnicos, evitando con ello la monotonía y la concentración de temáticas o actividades.

Así, a lo largo del curso el alumno fue adquiriendo conocimientos teóricos sobre historia de la fotografía, autores, lenguaje fotográfico, teoría y técnica de la cámara, que se compaginaron con ejercicios prácticos de forma evolutiva. Las sesiones prácticas, configuradas como talleres, se desarrollaron en lugares de interés al aire libre de ambas ciudades, elegidos por los profesionales de reconocido prestigio -alguno de carácter internacional- que se encargaron de los mismos. 


\section{Objetivos}

Antes de enumerar los objetivos que perseguíamos con esta experiencia docente no reglada, sería pertinente comenzar por aquellos no deseados, como eran -por ejemplo- adquirir un dominio de la técnica fotográfica o un manejo virtuoso de programas de retoque fotográfico. Entre los buscados estaban, reflejados literalmente así en el programa, los siguientes:

- Introducir nuevos horizontes y ámbitos laborales, tanto para arquitectos como para fotógrafos.

- Dotar al alumno de los conocimientos y técnicas necesarios para realizar todo el proceso propio de un proyecto fotográfico -entendido como un proceso integral que no se limita al instante de la toma y retoque posterior-, desde la planificación y toma fotográfica, hasta la presentación, entrega y exposición final del trabajo, pasando por la postproducción digital y la edición.

- Fomentar una actitud reflexiva en los estudiantes durante el proceso de desarrollo del proyecto fotográfico (Qué quiero contar y Cómo lo voy a contar).

- Desarrollar la capacidad crítica del alumno para valorar las imágenes por su calidad, frente a la cantidad que ofrecen a diario medios y redes sociales.

- Defender el poder de la fotografía como medio válido de expresión gráfica, con la que es posible exponer ideas, narraciones y análisis de la arquitectura.

- Iniciarles en las teorías de la composición y el diseño aplicados a la presentación del trabajo fotográfico como poderosa herramienta gráfica de narración, comunicación y representación de las ideas.

- Proveer un corpus teórico de conocimiento en el que convergen ambas materias, fomentando la multidisciplinariedad como forma de aprendizaje especializada para la formación de expertos.

- Mostrar referencias sobre la vinculación histórica entre fotografía y arquitectura, sobre las obras y grandes autores de fotografía de arquitectura, y sobre la construcción de la imagen de la arquitectura moderna a través de la fotografia.

- Evidenciar las similitudes existentes entre los procesos de descarte fotográficos y los procesos de decantación de ideas en el desarrollo del proyecto arquitectónico.

- Potenciar la capacidad creativa del alumno para expresar con la fotografia ideas, narraciones, análisis, de la arquitectura a través de la experimentación en los ejercicios prácticos, de las experiencias transmitidas por docentes y profesionales en las ponencias y del análisis de ejemplos de reconocidos autores en las sesiones teóricas.

- Entender la fotografía como vehículo con el que podemos "hablar". Lo que se dice con fotografías no se puede decir de otra manera. Los alumnos adquirirán, mediante la práctica, conocimientos técnicos que les familiarizarán con el uso de la cámara, la iluminación natural y artificial o la postproducción, y les proveerá de un serio conocimiento de cómo "se expresa" la fotografía. Y, por tanto, de cómo puede trascender la mera captura de imágenes y convertirse en un medio de creación

- Desarrollar un corpus teórico de conocimiento en el que convergen ambas materias, fomentando la multidisciplinariedad como forma de aprendizaje especializada para la formación de expertos.

Por último, se pretendía fomentar la comunicación, la coordinación y el trasvase de información y de conocimiento entre ambas Escuelas de Arquitectura - tan cerca pero a la vez tan lejos- afianzando el trabajo en red como motor de desarrollo autonómico, a la vez que se facilita el intercambio de experiencias entre investigadores y docentes que trabajan en los mismos temas. 


\section{Desarrollo de la innovación}

En el marco académico de las universidades andaluzas, Fundamentos de Fotografia y Arquitectura introduce una primera novedad al pretender la coordinación entre las escuelas de arquitectura de Sevilla y Málaga así como entre las Universidades de ambas ciudades. Se trata de un proyecto pionero que nunca antes se había propuesto en el marco andaluz. Como se ha señalado, existen un comité científico, un cuadro de profesores y un programa docente únicos para ambas sedes. No sin esfuerzo, es el profesorado el que se desplaza entre ambos emplazamientos para, a través de la docencia, establecer una conexión y conseguir una coordinación interprovincial de facto entre dos centros educativos con inquietudes compartidas. Finalmente, es el interés conjunto por la relación entre fotografía y arquitectura, el que ha motivado el desarrollo por primera vez en Andalucía de un programa educativo de carácter autonómico que aboga directamente por la colaboración interuniversitaria y por el desarrollo de una investigación y una formación coordinadas y basadas en el conocimiento.

A pesar del esfuerzo realizado por el profesorado y las insistentes gestiones que ha liderado la dirección del curso, las trabas administrativas han impedido que este primer año pudiese emitirse un reconocimiento conjunto para la formación recibida en ambas sedes, aunque existe una clara intención por parte de ambas universidades de resolver estas dificultadas de cara a la nueva edición que presentamos para el curso 2017-18.

Un segundo aspecto de vital importancia en la concepción del programa Fundamentos de Fotografía y Arquitectura desarrollado en el curso 2016-2017 ha consistido en desarrollar un programa que combine la formación teórica por una parte con el ejercicio práctico de la fotografía sobre el terreno por otra, y que además lo haga de forma entrelazada y continua a lo largo del curso. Estos dos bloques, teórico y práctico, habitualmente presentan dinámicas de trabajo muy diferentes y en todo momento nos ha parecido que nuestro programa de estudios debía caracterizarse por una perfecta sincronización entre ellos.

Al tratar un campo de conocimiento tan específico como la vinculación entre fotografía y arquitectura el curso se plantea con un carácter integral. Independientemente del formato y del número de horas -como se ha indicado, empezamos con un cuso de extensión universitaria para pasar a uno de formación continua y actualmente estamos proponiendo un curso de experto- el programa pretende ofrecer a los estudiantes un panorama suficientemente completo y equilibrado sobre las diferentes materias que componen este área de conocimiento.

La formación universitaria habitualmente se caracteriza por su carácter teórico en el que el grueso de la formación se desarrolla en la aulas y en el que los estudiantes adquieren un papel pasivo en el que reciben y acumulan información. Por mucho que se insista en dinamizar el espacio del aula, la formación teórica en muchas ocasiones se dirige de forma inevitable hacia estos modelos educativos. En cambio materias como la fotografia, y especialmente la fotografia enfocada hacia lo arquitectónico, se presentan como un marco inmejorable para introducir nuevas dinámicas de trabajo que incorporan el ejercicio práctico en el marco académico y cuyo carácter experimental no puede transmitirse con un proyector de diapositivas.

El conocimiento histórico, el manejo de programas informáticos, el análisis de referentes, etc. son campos que resultan imprescindibles para la correcta formación del estudiante dentro del programa que hemos diseñado, pero estos deben complementarse con el ejercicio práctico, con un "encuentro" con la realidad durante el periodo de formación y que, desde la experiencia directa se integren en un programa de estudios que aspira a ser integral. 
Analizando otros modelos educativos detectamos que es muy habitual que parte de la formación no reglada en fotografia se desarrolle en formato Workshop. Al margen del ámbito académico, desde diferentes centros no universitarios se ofertan programas que fomentan el encuentro entre profesionales y estudiantes de fotografía. Un modelo que durante años ha paliado la ausencia de una formación reglada en fotografía y ha permitido a los fotógrafos ampliar sus conocimientos a partir del intercambio directo con profesionales y con otros aficionados, sirviendo a su vez para tejer redes. Un claro ejemplo lo encontramos en los workshops que desde hace décadas han impartido reconocidos profesionales de la Agencia Magnum por todo el territorio nacional, con gran éxito de participación y de resultados.

Este modelo, en cambio, tiene un carácter casi exclusivamente práctico en el que un profesional y un grupo de alumnos conviven de manera intensa durante un corto periodo de tiempo, normalmente de 3 a 5 días, pero en el que apenas hay formación teórica. En Fundamentos de Fotografía y Arquitectura hemos querido combinar ambos referentes dentro de un mismo programa. Por una parte una formación académica que incide en el conocimiento reglado con un marcado valor teórico y, por otra, un modelo que se basa en la experiencia y el intercambio de conocimiento donde la inmediatez del ejercicio agudiza la capacidad de resolución de un proyecto fotográfico.

Más allá de que teoría y práctica se alternen dentro del cronograma formativo, hemos puesto especial atención en que el estudiante vaya adquiriendolos conocimientos de manera progresiva de manera que, cuando lleguemos a los tres talleres impartidos por profesionales que se intercalan en el programa, el estudiante pueda afrontarlos con el nivel de conocimiento necesario, tanto en cuestiones culturales como técnicas.

El programa teórico se estructura en torno a tres módulos temáticos:

- Historia y teoría de la fotografía de arquitectura. Grandes autores clásicos.

- Técnica y práctica fotográfica. Miradas cruzadas.

- Visiones contemporáneas, tangencias y exposición.

En el primero de ellos se hace un recorrido por la reciente historia de la fotografía prestando especial atención a aquellos momentos y autores en los que se produce una convergencia entre fotografía y arquitectura.

En el segundo se trabajan la parte técnica tanto en el manejo de cámara como en la edición y retoque utilizando programas informáticos. En este modulo se introducen pequeños ejercicios de clase para poner en práctica los conocimientos impartidos y, de esta manera, adquiere un carácter teórico-práctico.

El tercer módulo pretende situar al estudiante en un contexto actual que le permita comprender y afrontar la realidad del fotógrafo que trabaja la arquitectura, en todas aquellas facetas que oscilan entre la actividad profesional del reportaje de encargo el ejercicio de la práctica en un ámbito artístico.

Los contenidos de estos módulos no se imparten de forma cronológica sino que, igualmente, se ordenan en una estructura entrelazada en la que el estudiante atiende todos estos aspectos casi a diario.

Una vez adquiridos unos conocimientos mínimos en estas facetas, aproximadamente un tercio del tiempo total del curso, se van introduciendo los workshop dentro del programa. Estos se organizan en base a tres temáticas complementarias:

- Arquitectura

- Ciudad

- Paisaje

Esta estructura responde principalmente a dos criterios. Por una parte, una cuestión de escala en la que nos desplazamos del objeto arquitectónico, entendido como un elemento acotado y perfectamente delimitado, hacia 
el paisaje entendido como el "contexto" en el sentido más amplio del término. Por otra, la manera en la que el estudiante debe enfrentarse con cada una de estas temáticas. En estas tres sesiones dobles transita del registro más o menos riguroso de un elemento que se muestra claramente a través de formas y espacios reconocibles hacia un territorio más extenso como puede ser el de la ciudad, hasta llegar finalmente al más ambiguo de los tres, el paisaje, en el que la mirada no se centra solo en representar lo que ve sino que incorpora la complejidad del paisaje entendido como construcción cultural y en el que debe construir una imagen más personal de su entorno.

En el último tercio del curso la formación teórica se dirige hacia los diferentes formatos de visualización y difusión de la fotografía de arquitectura y que incluye ámbitos tan diversos como el almacenamiento y conservación de archivos fotográficos, el uso de imágenes en el campo editorial o la concepción y diseño de una exposición de fotografía.

Éste último ámbito, el de las exposiciones, adquiere un especial protagonismo dentro del programa porque nuevamente pone de manifiesto la proximidad y la interacción entre fotografía y arquitectura, aunque en esta ocasión se invierten los papeles y las imágenes se transforman en el motivo para la arquitectura.

\section{Resultados}

Consideramos que la mejor manera de evaluar los resultados obtenidos en el curso Fundamentos de Fotografía y Arquitectura es haciendo referencia al trabajo de los estudiantes, quienes finalmente han aplicado tanto la formación teórica, como la técnica y la práctica en sus propias realizaciones fotográficas dentro de los talleres. Y, dado el carácter del curso, creemos que en este apartado las palabras deben dejar paso a las imágenes.

Por tanto, mostramos a continuación una serie de fotografías realizadas durante los talleres que DuccioMalagamba, Fernando Alda y Jorge Yeregui han impartido en ambas sedes. En concreto el taller de Duccio Malagamba se centro en la temática Arquitectura y trabajaron este tema en la rehabilitación que Guillermo Vázquez Consuegra realiza del Monasterio de la Cartuja en Sevilla y en la biblioteca Manuel Altolaguirre diseñada por CDG Arquitectos en Málaga. 


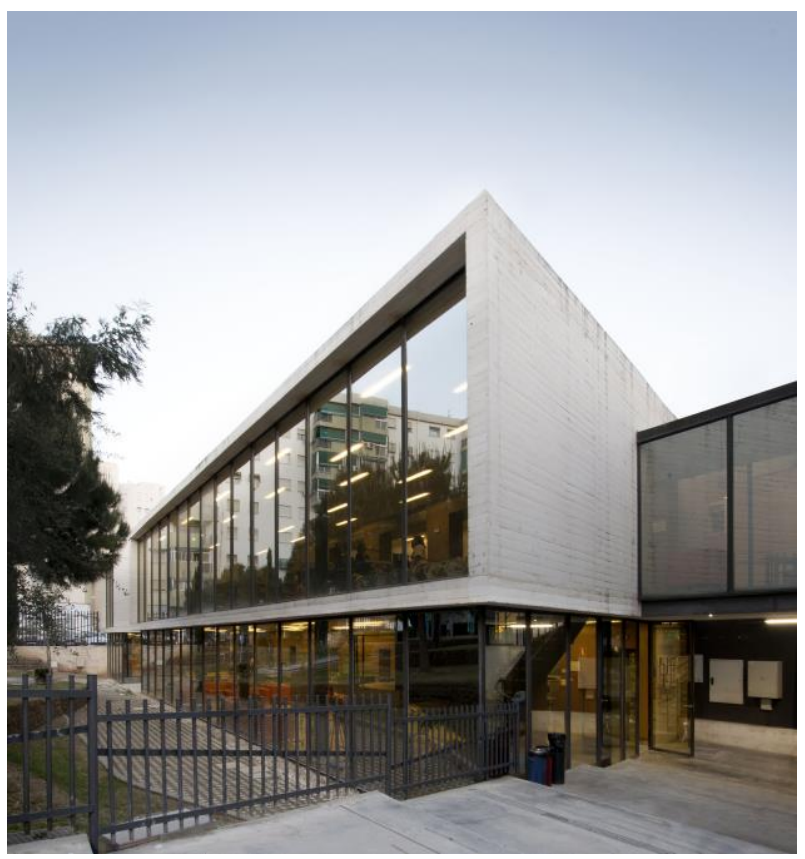

Fig. 1. Ignacio Álvarez Ossorio. Málaga. Biblioteca Manuel Altolaguirre.

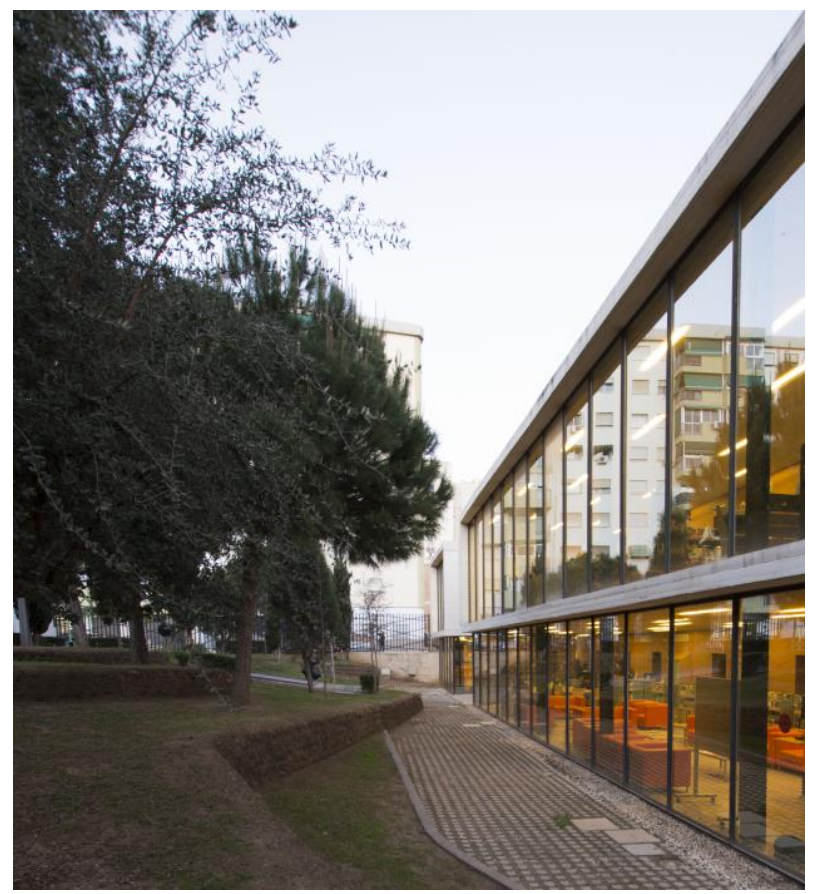

Fig. 2. Ignacio Álvarez Ossorio. Málaga. Biblioteca Manuel Altolaguirre.

En el taller de Fernando Alda trabajaron la temática Ciudad (espacio urbano) concentrándose en el campus universitario de Reina Mercedes en Sevilla y en el Muelle 1 del puerto de Málaga. 


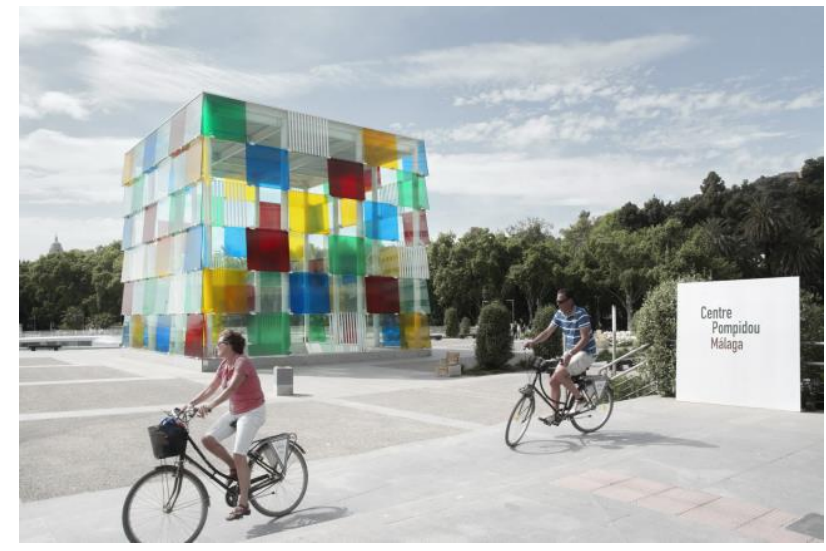

Fig. 3. Miguel Ángel Rodríguez Romero. Málaga. Muelle 1.

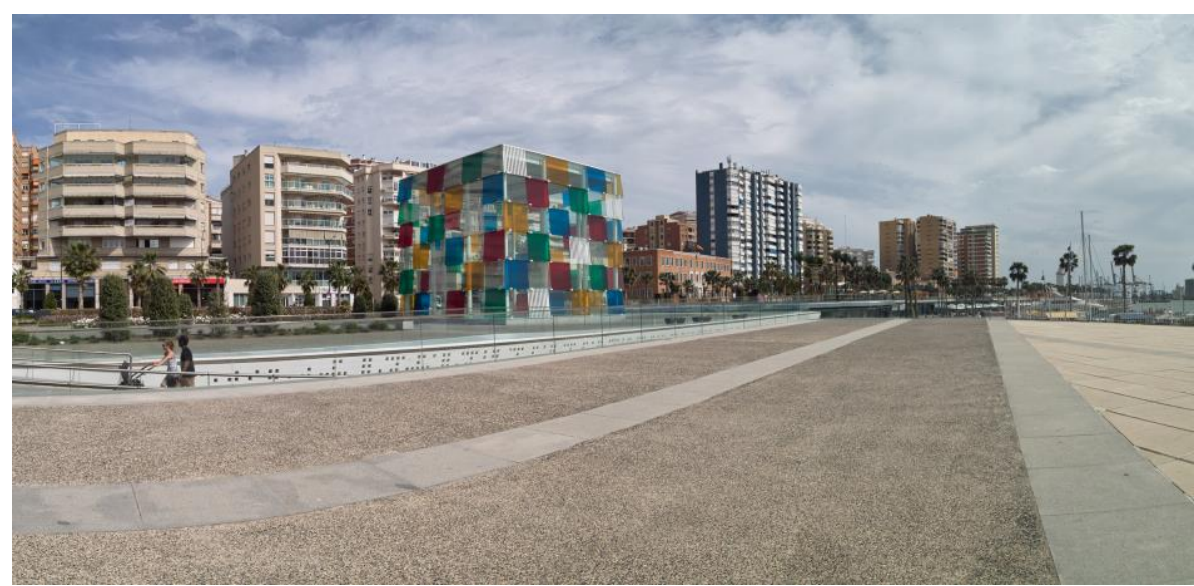

Fig. 4. Javier Gestoso. Málaga. Muelle 1.

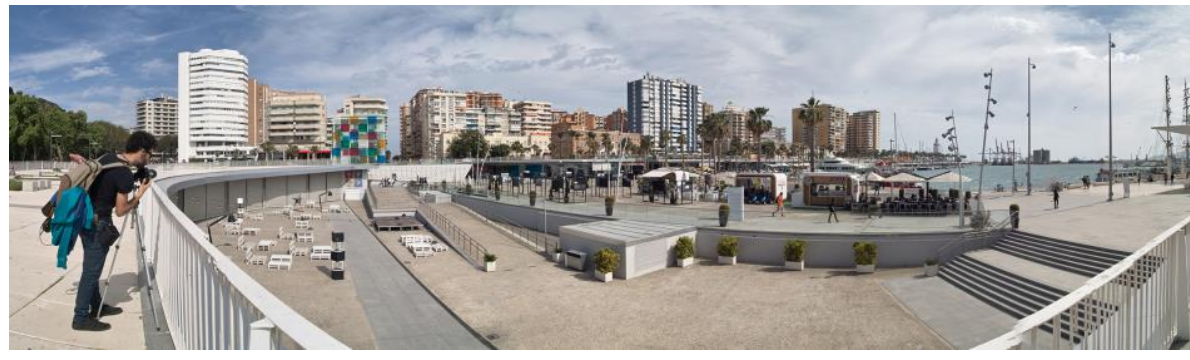

Fig. 5. Javier Gestoso. Málaga. Muelle 1.

En el taller de Jorge Yeregi trabajaron la temática Paisaje y se centraron en la conexión entre el paisaje urbano y agrícola a través del río Guadalquivir en Sevilla y en el recorrido litoral que va del Club Náutico El Candado hasta la Cala del Moral, en las proximidades de Málaga.

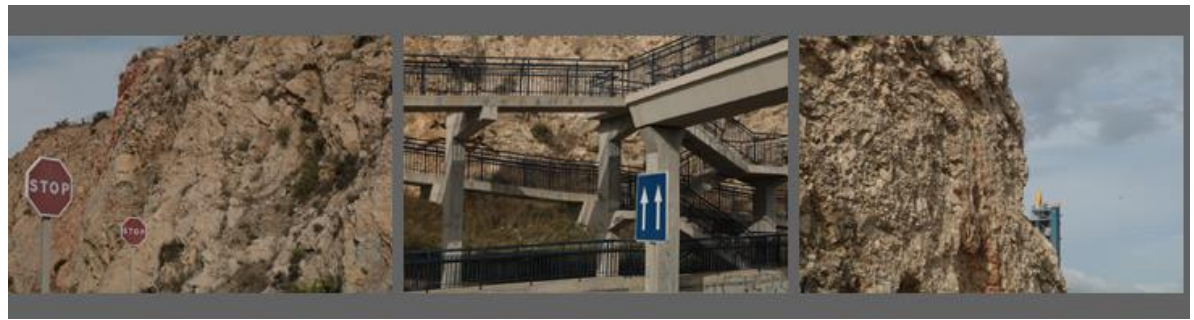

Fig. 6. Candela García Huber. Recorrido litoral. Málaga. 


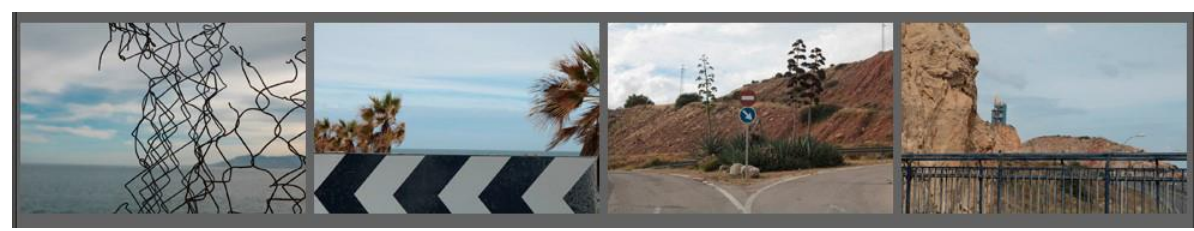

Fig. 7. Candela García Huber. Recorrido litoral. Málaga.

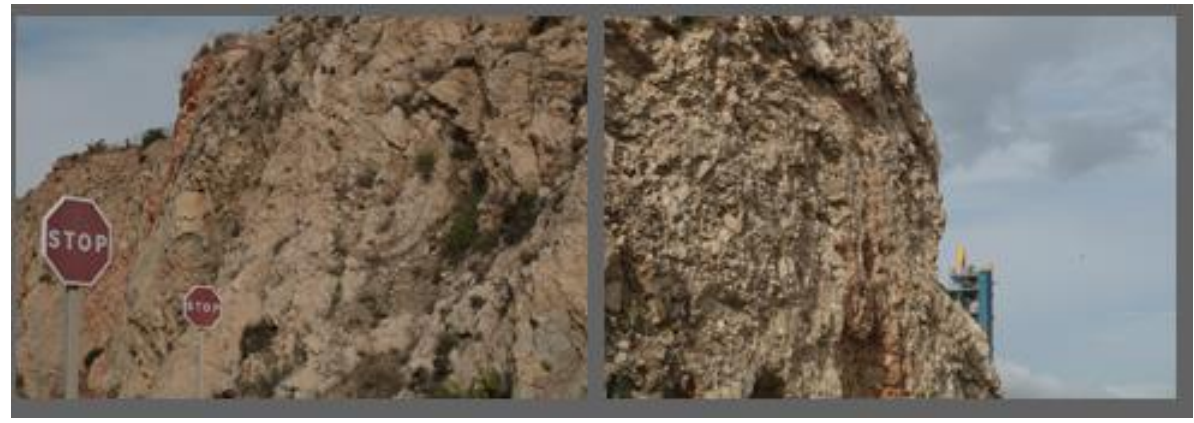

Fig. 8. Candela García Huber. Recorrido litoral. Málaga.

\section{Conclusiones}

Resultaría incompleto, llegados a este punto, expresar unicamente las impresiones positivas que la dirección del curso - que suscribe este documento- ha tenido una vez finalizado el mismo. Por ello, las completaremos con las recibidas de los alumnos que lo han cursado, y que fueron expresadas por varios alumnos en diversos momentos del curso.

Como primera impresión general, destacar el interés creciente por la materia existente en el ámbito universitario relacionado con la arquitectura, reflejado no tanto en el número de alumnos matriculados, sino en el interés y dedicación mostrado por todos ellos a lo largo del curso. Sin duda, de la estructura general del curso, ya reflejada en diversos apartados de esta comunicación, ha interesado más la práctica que la teoría, razón por la cual en la nueva estructura del que pronto saldrá a la luz, se ha reducido más si cabe la parte teórica en beneficio de nuevos talleres prácticos, no tan extensos en duración como los 3 desarrollados en Fundamentos. De los talleres prácticos, los alumnos han destacado la inigualable oportunidad de ver tutorizados y comentados personalmente sus trabajos por verdaderos maestros de la disciplina, como son Duccio Malagamba, Fernando Alda o Jorge Yeregui.

La temática y escala abordada en los talleres ha cumplido los objetivos, pues el alumno ha tenido que enfrentarse, de forma progresiva, primero con arquitecturas dispuestas a modo de pequeña ciudad; en segundo lugar, con trozos dispersos de ciudad inconexa que anuncian el final de lo construido y la periferia cercana; para terminar con la mirada fijada en torno a la periferia no construída del borde oeste de la ciudad, donde lo construído aparece ya lejano.

Nos proponemos como metas para la próxima edición, en el seno del Curso de Experto en Fotografía y Arquitectura, ampliar los horizontes laborales para arquitectos y fotógrafos, incidiendo en aspectos como la recuperación, documentación y difusión de archivos fotográficos; el control de la imagen proyectada a la sociedad -a través de los media- por parte de algunos estudios de arquitectura; o la presencia de la fotogrametría aplicada a la arquitectura patrimonial. Si aspiramos a convertirnos en master, debemos comenzar a explorar caminos que proporcionen la más amplia variedad posible de salidas profesionales. 
Fundamentos de Fotografia y Arquitectura

Las razones para seguir creciendo en esta aventuras son, precisamente, los comentarios recibidos de los alumnos, esperando que el boca a boca consiga mantener viva esta llama que nació de forma modesta hace dos años y que espera seguir creciendo con la presencia y el apoyo de los alumnos, verdaderos artífices de todo esto.

\section{Referencias}

Arquitectura Viva (2013). Modos de ver. No 153. Madrid: Arquitectura Viva S.L.

BENTON, Tim (2013). Le Corbusier. Secret Photographer. Zurich: Lars Müller Publishers.

BRAU, G. (2017). Visión fotográfica y lenguaje visual. Madrid: Terra Natio.

COLOMINA, B. (2010). Privacidad y publicidad. La arquitectura moderna como medio de comunicación de masas. Ed. en castellano. Murcia: Colegio de Arquitectos de Murcia.

FONTCUBERTA, J. (1997). El beso de Judas. Fotografia y Verdad. Barcelona: Gustavo Gili.

GARCIA CLARIANA, I. (2015). "Cuestiones de (Re) presentación. Fotografía y álbumes en la arquitectura de Fernando Moreno Barberá” en Fotografía y arquitectura moderna. Contextos, protagonistas y relatos desde España. Barcelona: Fundación Caja de Arquitectos, col. arquia/temas núm. 39.

JARDÍ, E. (2012). Pensar con imágenes. Barcelona: Gustavo Gili.

LÓPEZ, A. (2011). La mirada atenta. Sevilla: IUACC. Universidad de Sevilla.

LÓPEZ-RIVERA, J. (2015). Fotografía y arquitectura modernas. 1925-1939. Andalucía. Margaret Michaelis. Sevilla: Universidad de Sevilla y Junta de Andalucía, col. Kora No 28.

MARINA, José A..(2006). Teoría de la inteligencia creadora. Barcelona: Anagrama.

MARINA, J. (2014). "Mal visto, mal dicho", en Bergera, I., S. Lampreave, R. (Eds.), III Jornada de Arquitectura y Fotografía 2013. Zaragoza: Diputación de Zaragoza y Universidad de Zaragoza.

SERRATS, E. (2011). "Sin tectura ni grafía: arquitectura y fotografía”, en Bergera, I., S. Lampreave, R. (Eds.), I Jornada de Arquitectura y Fotografía 2011. Zaragoza: Institución Fernando el Católico.

SONTAG, S. (1981). Sobre la fotografia. Barcelona: Edhasa.

WARBURG, A. (2010). Atlas Mnemosyne. Tres Cantos: Akal.

ZABALBEASCOA, A. (2015). “¿Qué retrata quien fotografía arquitectura?” en Bergera, I., S. Lampreave, R. (Eds.), IV Jornada de Arquitectura y Fotografía 2014. Zaragoza: Diputación de Zaragoza y Universidad de Zaragoza.

ZUMTHOR, P. (2006). Atmósferas, entornos arquitectónicos, las cosas a mi alrededor. Barcelona: Gustavo Gili. 